\title{
"Não existe passado, apenas presente", notas sobre o trabalho de Yervant Gianikian e Angela Ricci Lucchi
}

\author{
Eduardo António Margarido*
}

Resumo: Comentário aos trabalhos sobre o arquivo de Yervant Gianikian e Angela Ricci Lucchi, tendo por tópicos o seu método, a sua concepção do tempo, os resultados da pesquisa e a plasticidade da sua forma. O discurso ideológico oculto na imagem e a abertura dessa mesma imagem ao que está para além do visível. Os punctum da imagem com enquadramento (ou os "sintomas") enquanto revelação de momentos históricos através de emoções (de momentos de loucura) e o seu respectivo enquadramento político.

Palavras-chave: máquina analítica; visível; visual; Barthes; punctum, sintoma; sinestésico; arquivo; temporalidades; modernismo; estatuto da interpretação; imagem dialéctica; "imagem clarão".

Resumen: Comentario a los trabajos sobre el archivo de Yervant Gianikian y Angela Ricci Lucchi, cuyos tópicos son su método, su concepción del tiempo, los resultados de su investigación y la plasticidad de la forma. El discurso ideológico oculto en la imagen y la apertura de esa imagen a lo que está más allá de lo visible. Los punctum de la imagen con encuadre (o los "síntomas") como revelación de momentos históricos a través de emociones (de momentos de locura) y su respectivo contexto político.

Palabras clave: máquina analítica; visible; visual; Barthes; punctum; síntoma; cinestésica; archivo; temporalidad; modernismo; estatuto de la interpretación; imagen dialéctica; "imagen deslumbramiento".

\begin{abstract}
Review of the work by Yervant Gianikian and Angela Ricci Lucchi on the archives, having by topics their method, conception of time, search results and the plasticity of their form. The hidden ideological discourse of the image and the opening of that image to what is beyond the visible. The punctum in the image with frame (or "symptoms") as a revelation of historical moments through emotions (of madness moments) and their political framework.

Keywords: analytical engine; visible; visual; Barthes; punctum; symptom; kinesthetic; archive; temporality; modernism; status of interpretation; dialectical image; "gleam image".
\end{abstract}

Résumé : Commentaire sur les travaux d'Yervant Gianikian et d'Angela Ricci Lucchi sur les archives, ayant pour topic leur méthode, leur conception du temps, les résultats de leur recherche et la plasticité de leur forme. Le discours idéologique caché dans

\footnotetext{
* Doutorando. Universidade Nova de Lisboa, Faculdade de Ciências Sociais e Humanas, Doutoramento em Ciências da Comunicação. 1069-061, Lisboa, Portugal. E-mail: edantcosmar@gmail.com
}

Sumissão do artigo: 15 de junho de 2016. Notificação de aceitação: 09 de agosto de 2016 
l'image et l'ouverture de cette image à ce qui est au-delà du visible. Le punctum dans les images avec encadrement (ou "symptôme"), tout en révélant des moments historiques à travers les émotions (de moments fous) et de leur encadrement politique. Mots-clés : machine analytique ; visible ; visuelle ; Barthes ; punctum ; symptôme ; kinesthésique ; archives ; temporalité ; modernisme ; le statut de l'interprétation ; image dialectique ; "image flash".

\section{"Não existe passado, apenas presente"}

Yervant Gianikian e Angela Ricci Lucchi vivem e trabalham juntos em Milão e esta frase resume a sua visão sobre o trabalho que desenvolvem com os arquivos.

Começaram o seu percurso no início dos anos 70, recolhendo, catalogando e construindo colecções de centenas de objectos, desde brinquedos antigos a imagens que, num primeiro momento, filmavam ou re-filmavam, recuperando a memória que inevitavelmente se encontrava aderente a esses objectos e imagens. Desta frase também se alcança o verdadeiro sentido da sua pesquisa com a história através da imagem: o reconhecimento da violência, a identificação das relações de poder impostas pela força. A violência do passado que se impõe ao presente.

Os objectos são pesquisados numa procura daquilo que representaram (o seu significado num contexto determinado, os gestos significantes no caso das imagens) num processo que poderíamos descrever como a procura da "aura" no sentido Benjaminiano, daquilo que os torna únicos e que é insusceptível de reprodução.

Nos seus primeiros trabalhos consideravam que esses objectos, por si, poderiam não ser suficientes para recuperar essa memória escondida e por isso faziam acompanhar as projecções/instalações por aromas de suporte difundidos na sala numa tentativa de ligação de factos históricos com emoções pessoais.

O imaginário era despertado por esses odores. Por exemplo em Alice profumata di rosa (1975) o odor a rosas estava presente, em Catalogo della scomposizione (1975) punham a circular o odor de naftalina mnemonicamente ligado à conservação de corpos. Sinestesicamente estes primeiros trabalhos remetem para uma empatia corporal entre espectador e imagem, para a materialidade da imagem, dos gestos, dos corpos, dos detalhes.

No entanto parece-nos que não está no espírito dos cineastas qualquer noção de "metacinema", no sentido de tornar visível o processo de feitura do material fílmico conduzindo à dissipação da "suspensão da descrença", nos termos em que foi feito o filme Onde jaz o teu sorriso, de Pedro Costa, uma escalpelização do processo de montagem do filme Sicilia, de Straub e Huillet. O que estará aqui em causa poderá ser um processo oposto, qual seja o 
de aprofundar a imersão fílmica do espectador para que os elementos que não são imediatamente perceptíveis o venham a ser. Por exemplo, em Catalogo... a violência dos corpos, a asséptica emocional do ambiente e dos processos de catalogação, são sublinhados (aprofundados) pelo cheiro da naftalina.

Os autores viriam a abandonar estas experiências sinestésicas num processo de concentração na autópsia da própria imagem, na descoberta das suas margens e dos eixos excêntricos. Findo este percurso inicial da carreira dos autores, centrado nas fotografias e filmes que recolheram até 1977, inicia-se nesse ano um outro centrado na descoberta dos filmes do documentarista italiano Luca Comerio (um documentarista semioficial do regime fascista), rodados em nitrato no início do século XX.

Esta descoberta acontece por um quase acaso, quando conseguiram salvar o espólio de um estúdio que se encontrava em processo de demolição. Para além dos filmes foram ainda preservados materiais e maquinaria laboratorial, tendo muita outra se perdido. Os autores recuperaram esses filmes, muitos deles já sem estarem em condições técnicas de ser exibidos devido à natural degradação do suporte pelo tempo, e re-filmaram (fotografaram) todos os "frames" com uma máquina artesanal por eles inventada e construída a que chamaram a "câmara analítica". Com esta câmara procederam a um trabalho de "tecelagem" dos "frames" antigos reeditando-os e revelando assim o escondido tecido histórico. Através deste método exploram os temas do passado para demonstrar como eles suportam o presente, como o tempo passado (neste caso no princípio do seculo XX) continua a moldar o presente.

Este processo de busca de significado visa iluminar a ideologia (discurso sobre uma realidade construída) que se encontra latente nessas peças fílmicas, por mais inocentes e inócuas que estas possam parecer. Para lá das imagens que se fixam, existem todos os intervalos entre elas que se assumem como lacunas a ser preenchidas, e é precisamente neste espaço que a resignificação e re-interpretação ocorrem, como nas imagens dos presos de 48 de Susana Sousa Dias em que os depoimentos actuais sobre esses registos do passado, burocráticos, oficiais, coloca sofrimento humano nas lacunas, vulcaniza essas roturas num manto de luta política e ideológica.

Citando: "Nós pensamos que apenas o presente existe e que para nós a memória é presente, não passado. É por isso que rejeitamos a categoria de arquivologistas; trabalhamos no presente e para o presente e não aceitamos a ideia do passado - aquilo que vemos em cada "frame" é o que vemos hoje". 1

1. Tradução livre de entrevista a Hans Ulrich Obrist. 
Esta asserção faz recordar aquilo que Roland Barthes chamava o "efeito do real" 2 da imagem fotográfica. Para Barthes a imagem fotográfica tem um particular tempo, o presente anterior. Fala do presente (o tempo em que é vista) e do passado (o tempo em que o evento foi fotografado). A fotografia é extraordinária, quase inexplicável, na maneira como combina estes dois tempos, parecendo repristinar a morte em vida.

Reagimos aos filmes de arquivo como se estivéssemos a ver os acontecimentos pela primeira vez, obliterando a distância cronológica que nos separa deles. No caso do filme dos autores Dal polo all 'Equatore nós vemos as tropas Italianas da I Guerra Mundial cruzarem os Alpes agora, o urso polar a ser atingido neste momento, imergimos assim numa realidade fílmica que é tanto real por ter sido filmada, apesar de relembrados pelo "slow motion" que estamos e ver um filme, analisando a acção de uma narrativa fílmica.

Os filmes de Angela e Yervant funcionam como máquinas do tempo que nos fazem regressar ao passado, experimentando-o como se fosse presente. $\mathrm{O}$ cinema permite a Angela e Yervant reduzir o ritmo a que o mundo, e os seus objectos, as suas coisas certas e erradas, vai desaparecendo. Permite-lhes mostrar o detalhe, o "reverse", as quebras na realidade fílmica e a manipulação dos elementos dessa realidade através das ampliações e do "slow motion".

Este método de tratamento do "arquivo" permite desconstruir para reconstruir e transformar os elementos fílmicos noutra coisa, o que significa, acima de tudo, reformatar esses elementos noutras categorias em que, v.g., o pormenor passa a determinante ou a margem passa a ser o centro.

Citando Hibon e Dominique Paini: "Enlarge, show details, extend (...) actions which, after manipulation, transform the original archives into indisputable and topical ideological discourse." " É este discurso ideológico, as relações de poder subjacentes às imagens de arquivo, sejam elas as relações de dominação colonial ou as inerentes ao militarismo na guerra, que são reveladas pelo particular método de Angela e Yervant.

Esta forma de "re-olhar" não só sublinha o "campo" que está fora da principal linha de visão/observação, isto é, os eixos excêntricos e marginais que se organizam fora do principal eixo visual e narrativo, como cria uma dimensão imaginária que está para lá dos gestos referenciados

O processo de análise, particularmente a repetição de "frames" que permite modular a experiência de visionamento articulada com a ampliação de partes dessa mesma imagem, remete-nos também para uma espécie de punc-

2. R. Barthes, L'effet de réel, in Communications, $\mathrm{n}^{\circ} 11,1968$, pág. 84-89.

3. D. Hibon, D. Paini, Del documentário fatto a mano, in P. Mereguetti, E. Nosei (eds.), Cinema anni vita: Yervant Gianikian e Angela Ricci Lucchi, Il Castoro, Milan, 2000, p. 100. 
tum Barthesiano em que momentos significativos e tocantes acentuam gestos, procedimentos e olhares.

No filme Inventario balcânico filmagens dos anos 20, 30 e 40 do século XX lançam uma panorâmica sobre a convivência das diversas comunidades e culturas em tempos de paz, uma convivência que sabemos dilacerada pelas guerras dos anos 90 e cujas origens se encontravam latentes já nestas filmagens.

Detenhamo-nos numa expressão dum "close-up" de uma rapariga de cabelo encaracolado constante do filme que, em enquadramentos frontais e laterais, nos é mostrada a interagir com o "cameramen" rindo e batendo as palmas.

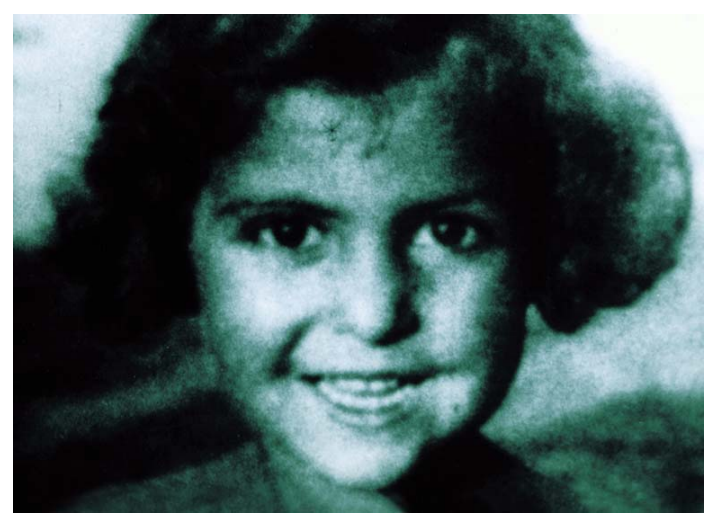

Enquanto a sua face desaparece do enquadramento, podemos ver o medo nos seus olhos. Este medo revela a construção falsa, postiça, que aquelas filmagens faziam da convivência das comunidades, demonstrando uma harmonia inexistente, encobrindo a violência que o autoritarismo militar já ali projectava. Uma imagem do passado que imerge no presente, e que já tudo explicava.

No ensaio Camera lucida de Barthes é discutida a fotografia do jardim de inverno, fotografia da própria mãe em criança e em que ele vê a sua verdadeira natureza, traduzida numa expressão que mais ninguém, que não o próprio Barthes, poderia captar. Esse "pedaço de conhecimento" ou de "sentimento" (punctum) é, para Barthes, a essência da fotografia, uma forma de loucura e compaixão que, para além de qualquer racionalidade, nos revela os fundamentos da humanidade.

É esta humanidade que vemos nos olhos da criança de cabelo encaracolado, ao mesmo tempo assolada pela loucura da encenação postiça e pela compaixão que o medo nos seus olhos suscita, revelando a violência contida naquela cultura e naquela sociedade. 
A magia deste filme, que acontece entre a fidelidade ao material de arquivo e manipulações que geram metamorfoses, revela-se no sentido fotográfico que já vimos com Barthes, o presente-anterior, em que a rapariga dos caracóis olha para nós para toda a eternidade, e que para a eternidade, no filme, ela se encontra ao mesmo tempo perdida e achada.

A fidelidade ao material de arquivo revela-se na manutenção da sua estrutura e ponto de vista (e mesmo da sua reconstrução), do seu campo (enquadramento) e até na sua materialidade. Sintomático, neste último aspecto, no seu filme $O h$ ! Uomo a compreensão do desgaste da pelicula nos fotoramas de duas jovens de seios desnudos (reveladora de um uso intensivo daquela parte da pelicula) como denunciadora de um olhar erotizado por parte da dominação colonial. Não se busca a resignificação no fora de campo, mas os significados escondidos no próprio contexto dos enquadramentos conforme eles foram originalmente tomados.

Uma outra noção importante no trabalho de Angela e Yervan é a sua noção de arquivos vivos. As testemunhas dos acontecimentos capazes de se relacionarem com e comentarem o acervo documental dos arquivos. A este propósito fazem referências a Freya StarK, na altura com 96 anos e autora de um livro intitulado The valley of assassins que constitui um olhar sobre as relações de dominação colonial dos europeus na Arábia e Médio-oriente. Questionada pelos autores sobre a razão da escolha desse título respondeu que entre eles (colonialistas) "were quite a few assassins".

Esta noção de arquivo vivo, e como já atrás visitado, sugere-nos o trabalho de Susana Sousa Dias e o seu filme 48 (2010). Neste filme ex-presos políticos relatam as suas histórias sobre fotografias de arquivo, fotografias que são os "clichés" policiais de quando foram presos. As imagens sonoras construídas pelas entrevistas (num ambiente cinematográfico, em termos de imagens propriamente ditas, muito austero) ao revisitarem esses arquivos sublinham, modificam, iluminam pormenores, mudam o sentido, um pouco à maneira da "câmara analítica".

Como diz a autora: “... estou a trabalhar com uma série de temporalidades mais complexa. A imagem remete-nos para um passado, mas também para um tempo presente a diversos níveis." " Diz ainda Susana Sousa Dias: "Por vezes somos nós que olhamos para a imagem, por outras olhamos para a imagem através do olhar de quem está a falar, por outras ainda é a imagem que olha para nós. Há uma resposta ideológica do próprio fotografado no momento em que tira a fotografia." 5

4. Entrevista a Manuel Halpern, publicada em Final cut e disponível em buala.org

5. Idem. 


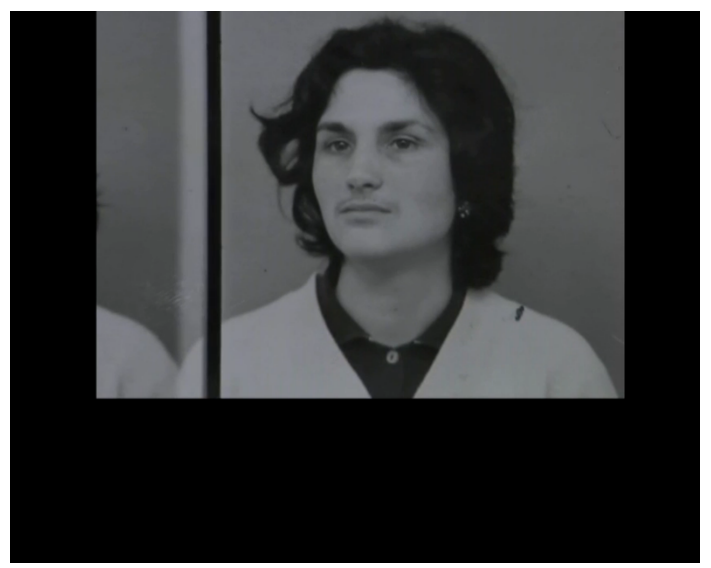

Para Sousa Dias a memória é revisitada, revivida e actualizada pelos depoimentos dos ex-presos, regressando ao presente como política e ideologia, como sofrimento humano, com aquela radical humanidade que já vimos existir no trabalho de Yervant e Angela.

Um outro aspecto interessante do trabalho de Yervant e Angela resulta do seu percurso se ter iniciado nas artes plásticas e de verdadeiramente delas nunca se terem radicalmente afastado. Já referimos a questão da materialidade existente nos seus filmes, a decomposição que resulta da acção do tempo no material de suporte que, além do seu significado histórico, não deixa de ter também uma dimensão plástica enquadrável nas correntes artísticas do seu tempo.

O "tratamento"/tintagem dos filmes, muitas vezes ácido, quase pop, fazendo lembrar Warhol nas suas impressões de ecrã, ou o uso de imagem em negativo que recorda as séries do mesmo autor sobre figuras icónicas (Mao, Marylin) remete para um universo de cultura pop e por aí para um questionar do modernismo na forma como este tradicionalmente via o arquivo, ou seja, como uma catalogação da história, arrumada em categorias, épocas, classes etc., fossilizando o passado.

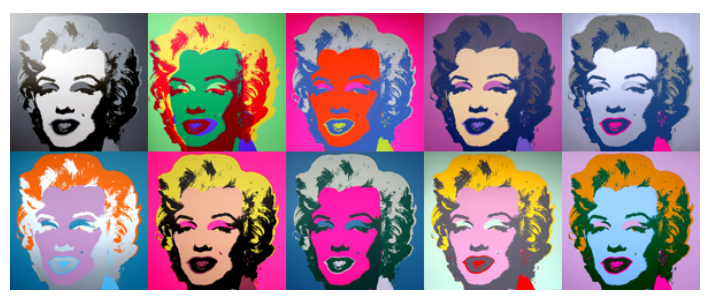



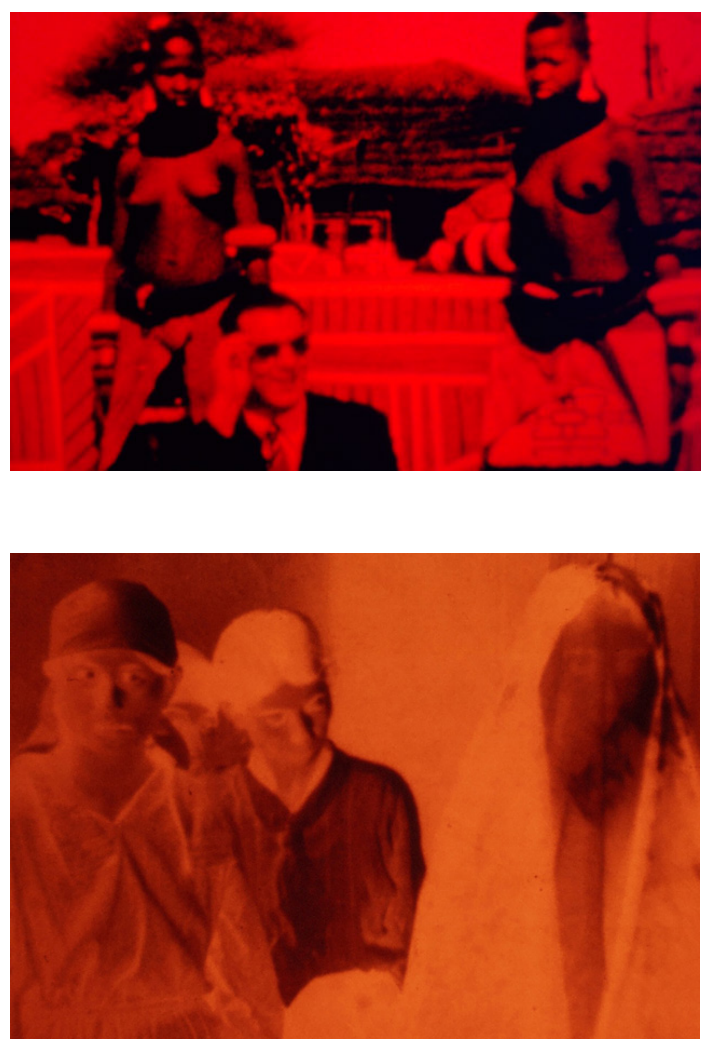

Se da história poderia o modernismo tirar ilações, remetia-a sempre para o seu lugar no passado que, na sequência da ideia de progresso, poderia justificar o futuro mas nunca ser considerada viva e presente.

A concepção de Yervant e Angela sobre o arquivo, nomeadamente o seu processo de interpretação de elementos do passado, remete para uma ideia de complexificação do olhar sobre estes elementos que o modernismo se limitava a racionalizar, classificar e organizar, com isso dando-nos deles uma mera simplicidade descritiva.

Esta ideia de complexificação interpretativa é central. As inúmeras tentativas de interpretar a rotura entre modernismo e pós-modernismo normalmente deixam de lado a consideração do que poderemos chamar do "estatuto da interpretação"(Zizek, 1994). Para Zizek uma e outra concepção concebem a interpretação como inerente ao seu objecto, ou seja, sem ela não haveria objecto artístico. Segundo o autor a rotura dá-se, precisamente, na relação existente entre o texto e o seu comentário. 
Os objectos modernistas são, por definição, "incompreensíveis". Eles funcionam como uma irrupção traumática no nosso quotidiano, resistentes a ser integradas no universo da ideologia dominante.

Depois desse encontro inicial de rotura a interpretação emerge como integrante desse choque e permite-nos fazer a reflexão necessária para adequar a obra às nossas categorias morais, sociais, de costumes, etc. Neste sentido podemos dizer que a interpretação é o momento conclusivo de cada ato de recepção.

Mas é também, para o modernismo, uma forma de controlo sobre o objecto precisamente através desse processo de catalogação, arrumação e arquivo. O pós-modernismo faz exactamente o oposto. O seu objecto são produtos com apelo de massas (essencialmente os que emergem da cultura popular) que aparentemente não precisam de qualquer mediação interpretativa.

No entanto se a interpretação modernista categoriza do ponto de vista humano a estranheza do objecto artístico, o pós-modernismo estranha essa placidez inicial complexificando a simplicidade aparente com que o objecto se deixa observar.

Sem essa complexificação nem é possível aceder à obra de arte. Sem essa complexificação também não seria possível aceder à violência histórica dos arquivos. Ao que traduzem em termos de relações de dominação e de poder.

A questão da interpretação, ou da resignificação, remete-nos para a ideia dos "ready-made" de Marcel Duchamp, corolário da apropriação de objectos já existentes, objectos de produção industrial e com uma funcionalidade prática, dando-lhes um outro sentido, passando da consideração da sua forma à reflexão sobre o significado que os mesmos podem adquirir em diferentes contextualizações.

Para compreender um objecto, nomeadamente uma obra de arte, todo o seu contexto, toda a sua espessura histórica, todos os seus mecanismos de legitimação e validade são chamados a dar-lhe sentido, e esse sentido não é mais a expressividade de um autor mas, essencialmente, a leitura que o receptor desse objecto dele possa fazer.

Yervant e Angela assumem os seus objectos de arquivo como "readymade's" sobre os quais trabalham, objectos constituídos por filmagens, fotografias, brinquedos, objectos encontrados, objectos privados, manipulando-os por forma a revelar a sua contextualização e desse modo perceber e permitir uma leitura desses objectos que possa suscitar reflexão.

$\mathrm{O}$ estudo e re-filmagem destes objectos conduz à descoberta de elementos escondidos e de outros que se encontravam adormecidos. 
Ou, dito de outro modo, do visível somos conduzidos ao visual, a abertura do "frame" ao local, ao desejo e aos "sintomas" do que está oculto (DidiHuberman, 1990: 64). Esta noção de sintoma, que Didi-Huberman vai buscar a Freud, é uma maneira nova e decisiva de ver, uma forma de nos ser imposta uma reflexão sobre o não-saber enquanto momento de rotura do visual (Didi-Hubermam, 1990: 176). O sintoma vai assim consistir, no âmbito da visibilidade, num momento, na imprevisível e imediata "passagem de um corpo à aberração de uma crise". (Didi-Huberman, 1990: 306), mas uma crise "paradigmática" e significativa que revela uma estrutura e um fantasma que se encontra dissimulado. Para o compreendermos teríamos que voltar novamente à rapariga dos caracóis de Inventario Balcanico, à sombra momentânea nos seus olhos e ao que esse fugaz momento revela.

Neste passo também recordamos o conceito de imagem dialéctica de Benjamim (2006) em que este afirma que: "A imagem dialéctica é uma imagem fulgurante. É então como imagem fulgurante no Agora da cognoscibilidade que é preciso reter o outrora".

É evidente o paralelo que existe entre o pensamento de Benjamim e a maneira como Yervant e Angela olham para o passado. Para Benjamim a imagem dialéctica é uma imagem crítica, pois é uma interpenetração "crítica" do passado e do presente, afloramento sintomático (aqui transparece Didi-Huberman) na memória colectiva e inconsciente, aquilo que precisamente produz a história. Não existe passado, apenas presente. As "imagens fulgurantes" do passado a construírem o conhecimento do presente, muitas vezes como sintomas, fantasmas, "punctum", penetrando o agora.

Citando ainda Benjamim: "Não é preciso dizer que um passado esclarece o presente ou que o presente esclareça o passado. Uma imagem pelo contrário é aquilo em que o Outrora encontra o Agora num clarão para formar uma constelação" (2006: 479-480).

O que é também paradoxal neste método de Yervant e Angela é que a imagem que é filmada representa uma imagem fotográfica, que por sua vez representa um homem com uma espingarda, alguém a andar, etc.

Deste modo a sua simbologia oscila, perturba-se pelos níveis de significado, espaço e tempo que se encontram interpenetrados. Uma experiencia quase táctil é proporcionada pela maneira como a própria degradação do suporte dos objectos é incluída na sua resignificação, ampliada pelo uso da "slowmotion", construindo uma curiosa manifestação do tempo, algo excessivo mas intimamente experimentado. Imagens de imagens.

O hoje com o "húmus" do passado. 
"Para nós não existe passado, só presente", a frase com que iniciámos esta reflexão é neste contexto que deve ser compreendida, num sentido de um continuum histórico em que a violência, nas mesmas formas e com as mesmas causas, permanece, constatada na materialidade dos corpos desfigurados, na persistência dos gestos de dominação e poder, na permanência de um mundo cujas imagens são políticas e com significado e discurso ideológico.

\section{Referências bibliográficas}

Bellour, R. (1995). L'arrière-monde. Cinémathèque, (8), Outono.

Benjamim, W. (2006). Paris, capitale du XIX siécle: le livre des passages. Paris: Cerf.

Clifford, J. (1988). The predicament of culture: twentieth-century Etnography, Literature and Art. Cambridge: Harvard University Press.

Didi-Huberman, G. (1990). Devant L'image. Paris: Éditions de Minuit.

Farge, A. (1989). Le goût de l'archive. Paris: Le Seuil.

Geertz, C. (1973). Thick discrition: toward an interpretive theory of culture. In The interpretation of cultures. New York: Basic Books.

Gianikian, A. (2004). Ricci Lucchi - Nos cherchons. Cahiers du cinéma, (590), Maio.

Lipzin, J.C. (1981). Engaging the olfactory. The cinema news.

Nash, M. (2004). Experiments with truth. Philadelphia: The fabric workshop and museum.

Uriel Pinho, G. J. \& Lima, R. (2012). Modernidade, pós-modernidade e cinema. Revista Anagrama, Edição 3, ano 5, Março-Maio.

Zizek, S. (1994). Todo lo que usted siempre quiso saber sobre Lacan y nunca se atrevio a perguntarle a Hitchcock. Buenos Aires: Ed. Manantial.

\section{Filmografia}

Alice profumata di rosa, 8 mm, cor, mudo, aroma de roda, 10‘, 1975.

Catalogo della scomposizione, $8 \mathrm{~mm}$, cor, mudo, aroma de naftalina, 10“, 1975.

Dal Polo all 'Eqatore, $16 \mathrm{~mm}$, cor, som original por Keith Ullrich e Charles Anderson, 101', 1986.

Inventario Balcanico, $16 \mathrm{~mm}$, cor, som em colaboração com Charles Anderson e Djivan Gasparyan, 62‘, 2000. 
Oh! Uomo, $35 \mathrm{~mm}$, cor, som em colaboração com Marina Marini e Luis Agudo, 72‘, 2004. 